This manuscript has been accepted by IEEE for publication (C) 2008 IEEE. Personal use of this material is permitted. Permission from IEEE must be obtained for all other uses, in any current or future media, including reprinting/republishing this material for advertising or promotional purposes, creating new collective works, for resale or redistribution to servers or lists, or reuse of any copyrighted component of this work in other works. The full reference is:

Fault Development in Wet, Low Voltage, Oil-Impregnated Paper Insulated Cables

IEEE Trans DEI 15 Issue 2, (2008) 484 - 491

S M Rowland and M Wang

DOI: $10.1109 /$ TDEI.2008.4483468 


\title{
Fault Development in Wet, Low Voltage, Oil-Impregnated Paper Insulated Cables
}

\author{
Simon M. Rowland and Miao Wang \\ The School of Electrical and Electronic Engineering, \\ The University of Manchester, \\ PO Box 88, Manchester, M60 1QD, UK
}

\begin{abstract}
Few studies have been carried out on the failure processes of low voltage distribution cables. This is mainly due to their excellent track record of high reliability, and their use of traditional technologies. Growing quantities of aged cable within the network now make management of these assets an important issue. This paper describes measurements of leakage current, partial discharges and arc formation within $400 \mathrm{~V}$ oil-impregnated paper insulated cable structures which have been artificially wetted by immersion in bulk water. A generic picture is produced to show the gradual evolution from a leakage current through discharge growth to final catastrophic failure. Rapid changes to the core temperature of a wet cable are shown to produce transient, high levels of leakage current. It is also shown that by increasing the core temperature more slowly these high levels can be reduced. It is suggested that the characteristics of individual arcs within successive half cycles may provide a basis for predicting whether an incipient fault will lead to failure in the short term.
\end{abstract}

Index Terms - Cable insulation, underground power distribution lines, dielectric breakdown, paper insulation, moisture, aging, partial discharges, arc discharges.

\section{INTRODUCTION}

LOW voltage distribution cables have been one of the most reliable aspects of the electricity distribution system. The voltages at which they operate (for example $415 \mathrm{~V}$ phase-tophase) are so low that insulation is required to withstand only a few hundred volts per millimeter. This is a low level compared with high- or even medium-voltage cables, which see design fields an order of magnitude higher. These low fields and voltage mean that many of the aging mechanisms associated with higher voltage cables do not occur. Thus the growth of electrical trees or partial discharge activity within voids are not expected in any normal operating conditions. Because these 'traditional' high voltage mechanisms of aging do not occur, and because of their historic reliability, very little work has been focused on aging or failure of $\mathrm{LV}$ cables.

In urban environments there is now an ever aging population of cables. In London for example, cables are in service that were installed 100 years ago. The issue of asset management is thus becoming a key concern. Optimizing asset management and replacement presents a major challenge in the absence of historical failure data. One key issue is the ingress of water into a cable once the sheath has lost integrity. In practice, moisture is likely to originate after damage to the

Manuscript received on 30th May 2007, in final form 4 September 2007. lead sheath. Such damage typically arises from corrosion or accidental dig-up. The diverse materials and structures employed over the years [1] make a chemical analysis approach, which might be used in a more refined situation, difficult since controls against which to judge aged samples do not exist.

It has previously been reported that low voltage cables in service can experience transient or incipient discharges, from which the cable can apparently recover, only to fail some time later [2]. In addition it has been established that this type of cable allows moisture to ingress insulation to values of over $20 \%$ by weight if directly exposed to moisture [3]. These values are far in excess of those expected in modern polyethylene insulated cables [4]. From studies on higher voltage cables [5] and transformer insulation systems it is clear that water ingress impacts dielectric performance of oilbased systems negatively [6-8]. Both dielectric permittivity and loss are enhanced in the power frequency range, and dc conductivity is increased markedly [9-11]. Also dielectric breakdown strength is reduced [12]. In addition, other processes such as corrosion of metal elements are accelerated by the presence of moisture. We know therefore that progress of water ingress can be a critical element in failure, despite the dearth of work reported on low voltage distribution cable failure in particular. 
This study aims to outline the development of discharge activity within a cable core as a result of moisture permeation, and how such discharges develop into dielectric failure. Departing from the traditional approach for high voltage products, in this study increasing the voltage has not been used as an accelerating parameter. Working voltages have been employed, and failure has been accelerated by high levels of exposure to moisture.

\section{EXPERIMENTAL}

The cable studied is a paper-insulated, lead-covered (PILC) belted design with four $185 \mathrm{~mm}^{2}$ stranded aluminum cores and oil-impregnated paper (OIP) insulation [1, 3]. Figure 1 illustrates the cable structure. Work reported here is focused on the sector-shaped, stranded aluminum conductor and the associated helically wrapped OIP layers. The insulation around each sector-shaped core is formed by seven wrapped paper insulation layers, forming insulation $0.89 \mathrm{~mm}$ thick. OIP layers overlap by between 15 and $50 \%$, and a small slot (about $1 \mathrm{~mm}$ wide) results between adjacent paper strip edges on the same layer [3]. The variability of the overlap illustrates the relatively low level of control in manufacture compared with higher voltage products. The belt insulation consists of four further layers of OIP.

The test circuit is illustrated in Figure 2. The sample configuration shown is for a single core extracted from the cable. In this case the core is directly submerged in water or a saline solution. In some cases the aluminum stranded core was heated from both ends by thermostatically controlled heaters, which controlled the core temperature to $\pm 2{ }^{\circ} \mathrm{C}$.

The sensors used in the circuit included a DVM, a 'clip-on' current transformer, an $\mathrm{HV}$ voltage divider, a Rocoil transducer and an inductive probe PD detector. The first two

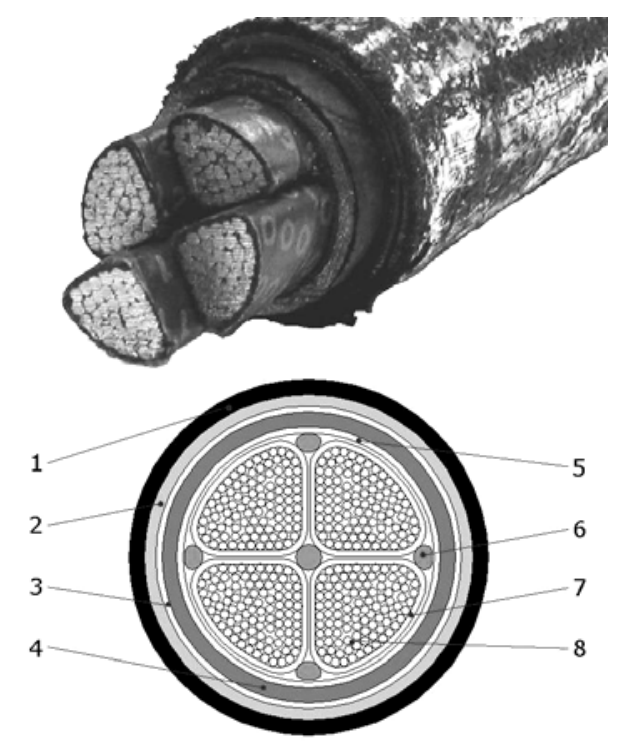

Figure 1. LV cable structure and cross-section: 1. bituminized outer cover; 2 . steel armour; 3. OIP insulation layer; 4. lead sheath; 5. OIP belt insulation; 6 . fillers; 7. OIP core insulation; 8. compacted stranded aluminium conductor.

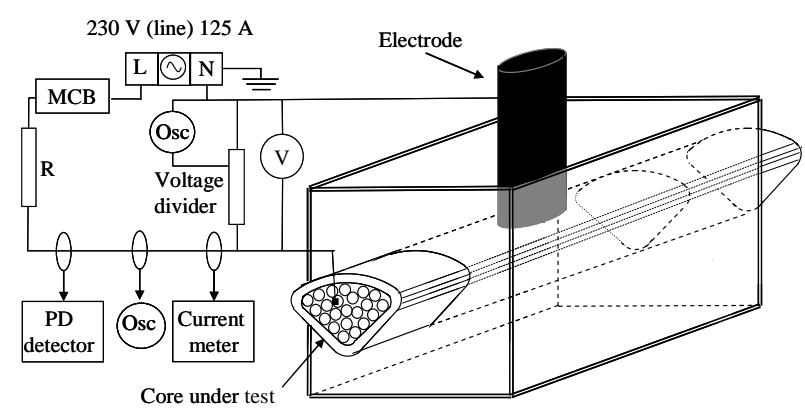

Figure 2. Test circuit. For clarity the heating elements inserted into the core are not shown.

instruments gave the numerical values of the voltage and current, and the latter three were connected to a $500 \mathrm{MHz}$ digital storage oscilloscope to record the voltage and current waveforms. The oscilloscope sample rate was set to $500 \mathrm{kHz}$. The Rogowski coil current transducer can measure alternating currents over a frequency range from less than $0.1 \mathrm{~Hz}$ to $1 \mathrm{MHz}$. This transducer was also used for measuring large arc currents. The inductive PD sensor has a frequency response of $100 \mathrm{kHz}$ to $20 \mathrm{MHz}$, which was particularly suitable for detecting partial discharges occurring during the failure process.

The use of a Rocoil current transducer and inductive PD sensor provided a sensitive tool for investigation of the high frequency components in the discharge signals. The waveforms of supply voltage, arc current, and partial discharge current were monitored continuously on the oscilloscope. The passive resistor, $\mathrm{R}$, was $5 \Omega$ and ensured the current did not exceed an rms value of $46 \mathrm{~A}$ (an amplitude of $65 \mathrm{~A}$ ). The resistor consisted of many elements in parallel and was of large mass, ensuring its resistance was not changed by short periods (seconds) of such high current (equivalent to 10 $\mathrm{kW})$.

The brass earth electrode, which had sharp edges removed, was in direct contact with the core surface under the moisture. The immersed length of core was $20 \mathrm{~cm}$.

\section{CURRENT THROUGH WET CORES}

Core samples were soaked in tap water $(0.09 \mathrm{mS} / \mathrm{cm})$ or salt water $(1.0 \mathrm{mS} / \mathrm{cm})$ at room temperature or with their cores elevated to a constant $75{ }^{\circ} \mathrm{C}$. If the core was heated to $75{ }^{\circ} \mathrm{C}$, the water attained a steady temperature of $65^{\circ} \mathrm{C}$ after 2 hours. Experiments reveal that arcs initiate soon after the value of leakage current exceeds $100 \mathrm{~mA}$, or the insulation conductance rises beyond $420 \mu \mathrm{S}$. Then a series of arcing events occur after the arc initiation, which severely damage the insulation leading to catastrophic breakdown.

Figure 3 shows the development of current for three different exposure conditions. Heating the core enhances both the moisture ingress and increases conductivity. Increasing the conductivity of the water leads to a faster transition from the insulating to conducting state. Figure 4 shows moisture content measured within each insulation layer by Karl-Fischer titration after the current had reached a prescribed value for 
four different samples [3].

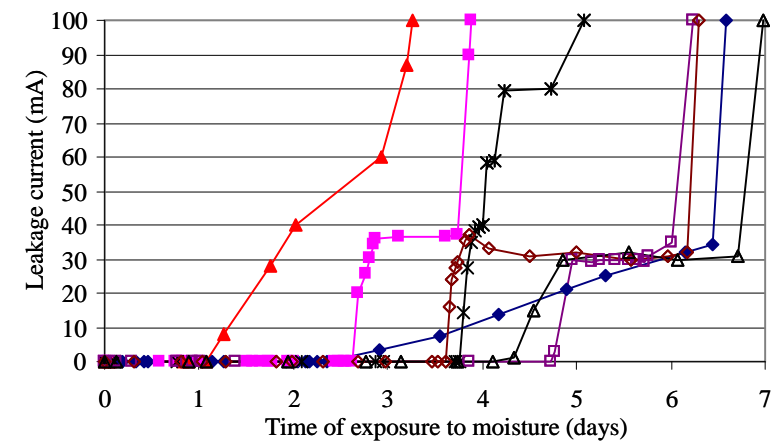

b)

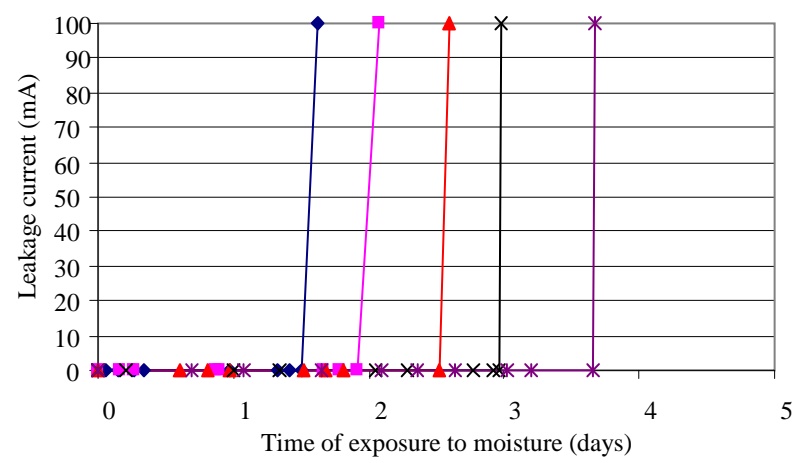

c)

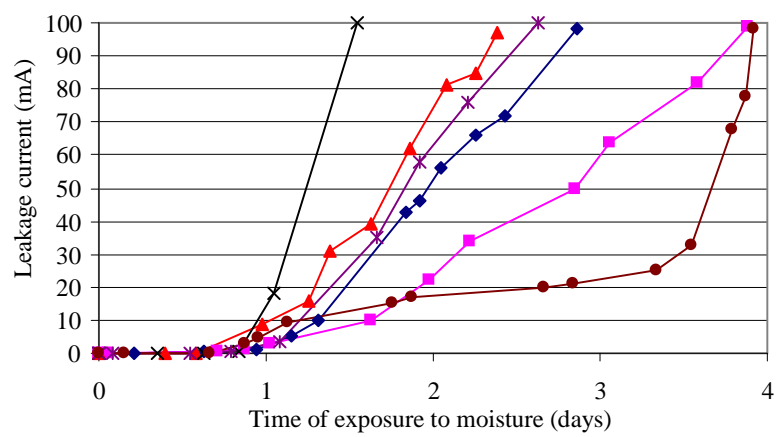

Figure 3. Current measured over time for cable cores soaked in a) tap water, with core at $20{ }^{\circ} \mathrm{C}$, b) salt water at $20{ }^{\circ} \mathrm{C}$, c) tap water, with core at $75{ }^{\circ} \mathrm{C}$. The data shown is for nominally identical samples.

Conductivity values can remain at a constant elevated value for a significant period of time during the whole process. In Figure 3a, four of the samples' leakage currents can be seen to have sat at 30 to $40 \mathrm{~mA}$ for more than 24 hours before increasing rapidly. Raising the temperature reduces the time taken to get to $100 \mathrm{~mA}$ in tap water, and saline solution gives a much faster rise in current from a few $\mathrm{mA}$ to $100 \mathrm{~mA}$. In all cases shortly after the current reached $100 \mathrm{~mA}$ intensive discharges occurred leading to catastrophic failure.

\section{ARC DEVELOPMENT IN WET CORES}

Figure 5 shows photographs of laboratory tested insulation after being tested in tap water. The current exceeded $100 \mathrm{~mA}$ in each case, leading to discharges within the cable. In cases of Figures $5 \mathrm{a}$ and $5 \mathrm{~b}$ the insulation has been unwound from the core for inspection as described previously [3]. The damage

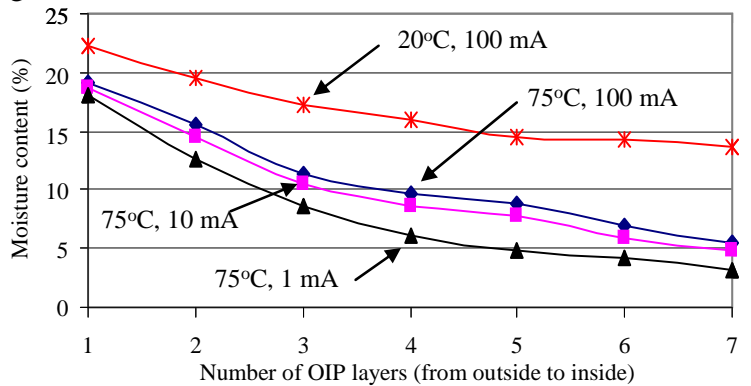

Figure 4. Moisture content of insulation by layer at: $100 \mathrm{~mA}$ with the core at $20^{\circ} \mathrm{C}$, and $100 \mathrm{~mA}, 10 \mathrm{~mA}$ and $1 \mathrm{~mA}$ respectively for a steady core temperature of $75^{\circ} \mathrm{C}$. Moisture content errors are $\pm 5 \%$ of the value quoted.

a)

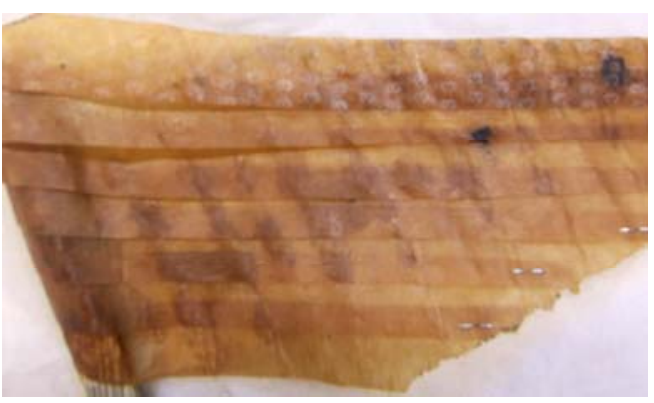

b)

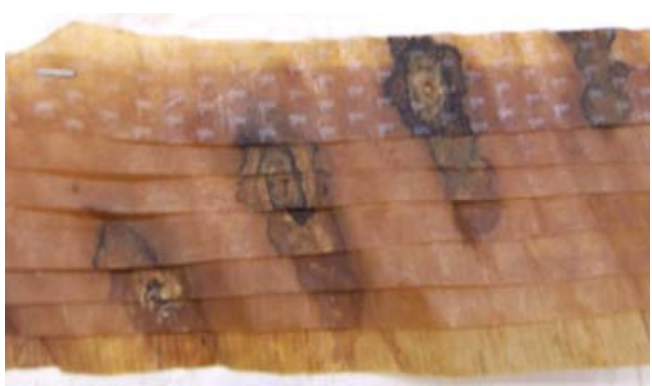

c)

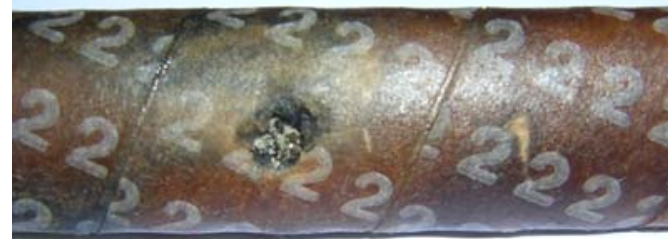

Figure 5. The physical results of discharge activity. In a and b the insulation has been unwound from the core.

has been allowed to progress furthest in cases b and c. Damage is worst in the outer layers of the insulation.

Generally, once partial discharges (PD) have started, their intensity gradually, but intermittently, increases. This means discharges can become weak or disappear for some time, and then increase again. After a period, visual and audible PD activities can be observed during intensive PD stages. Figure 6 shows PD activities captured by the inductive PD sensor before arc initiation. 


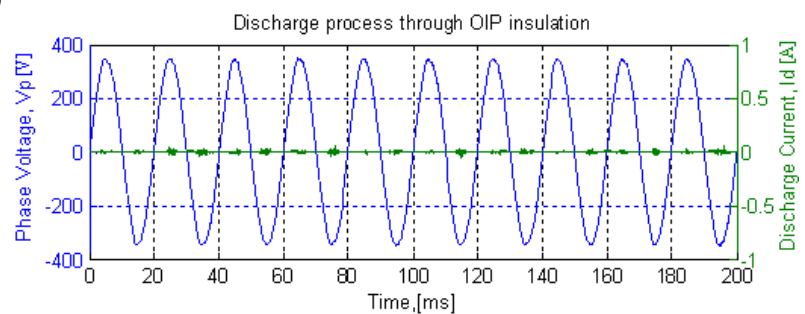

b)
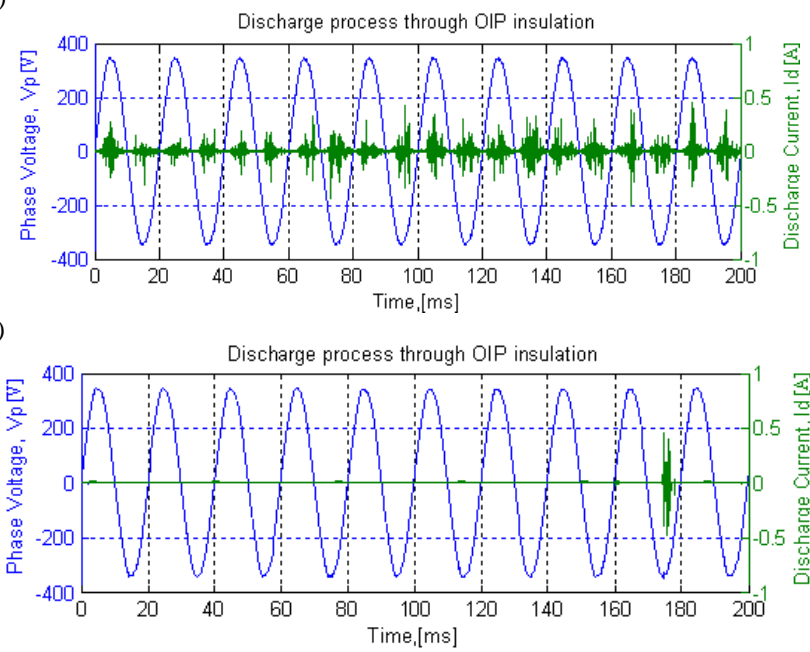

Figure 6. Examples of pre-arcing PD activities captured as the damage progresses. Cable cores immersed in tap water at room temperature a) hours before arcing occurs, b \& c) minutes before arcing occurs.

As PD activity increases in intensity, it eventually develops into arcing which causes a regulation of supply voltage. The PD intensity typically reduces slightly after the arc initiation, and then increases intermittently again to a higher level, followed by repeated episodes, each showing a higher intensity than the previous one. After the arc initiation, the subsequent arcs occur sporadically and then tend to become more regular for a period.

Arc development was captured by the Rocoil current transducer. Based on a large number of arcing tests, there are no apparent differences in terms of arc waveforms using tap water, and salt water solutions or between the room temperature and elevated temperature cases.

After arc initiation comes a sporadic arcing period, in which the arc strikes occasionally. The duration of the 'sporadic' arcing stage (which may be hours) varies between samples under the same conditions.

As the insulation deteriorates further, the arc strikes more frequently leading to the 'intermittent' arcing stage. Figure 7 shows examples of intermittent arcs obtained from the tests. The duration of the 'intermittent' arcing stage ( minutes) is shorter than the 'sporadic' arcing stage.

The non-linear relationship between instantaneous arc current and arc conductance changes as an arc develops. The continuous arcing event shows a regular change in consecutive

a)

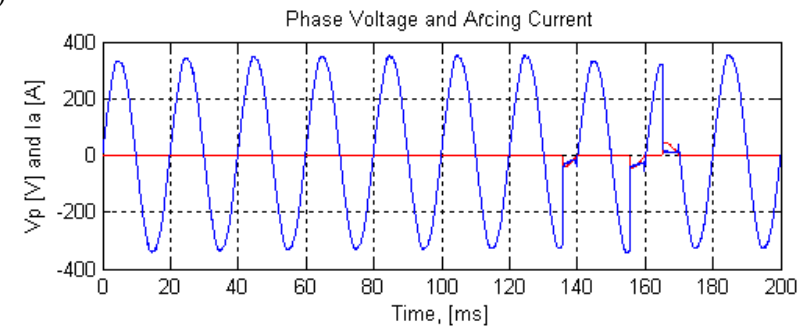

b)
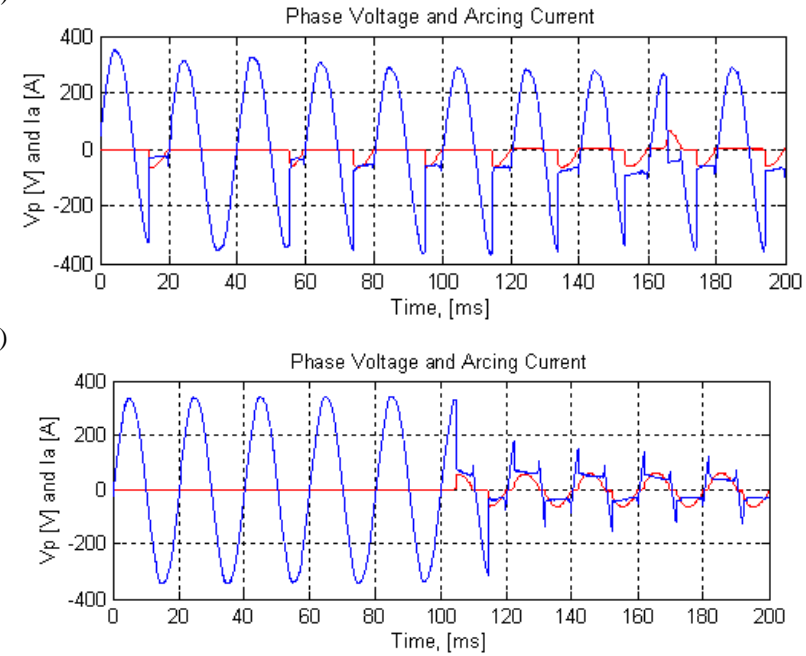

Figure 7. Waveforms of intermittent and continuous arcs. Cable cores immersed in tap water, with the core elevated to to $75^{\circ} \mathrm{C}$. a) and b) $\sim$ minutes before breakdown, c) catastrophic failure.

arcs in both positive and negative cycles. Although current through the arc in each cycle is related to the source impedance (in this case limited by the $5 \Omega$ resistor), the arc conductance directly reflects the relationship of arc current and arc voltage, and it can be used as an indicator to illustrate the changing trend over the arcing cycles, as shown in Figure 8. The lower half of each loop in Figure 8 characterises the first half of the arc and the upper part the extinguishing half, in which the conductance is always higher.

It can be observed that the arc current and arc conductance are different in adjacent positive and negative half cycles. The subsequent arcs tend to have higher arc conductance and reduced hysteresis. For adjacent half cycles (1st and 2nd, 3rd and 4th, 5th and 6th, 7th and 8th) the arc current and arc conductance is higher in the negative half cycle than in the positive one. Based on the continuous arcs, it is apparent that the arc conductance and arc current in a half cycle are enhanced as a result of recent arcs in the same location.

If an arc strikes continuously, the ignition and extinction paths exhibit less hysteresis. In descriptive terms, the butterfly wings of Figure 8 become narrower, indicating the end of life of the cable, where intensive electrical discharges can 'burn' the cable into a fault which in a service situation would require immediate replacement. 


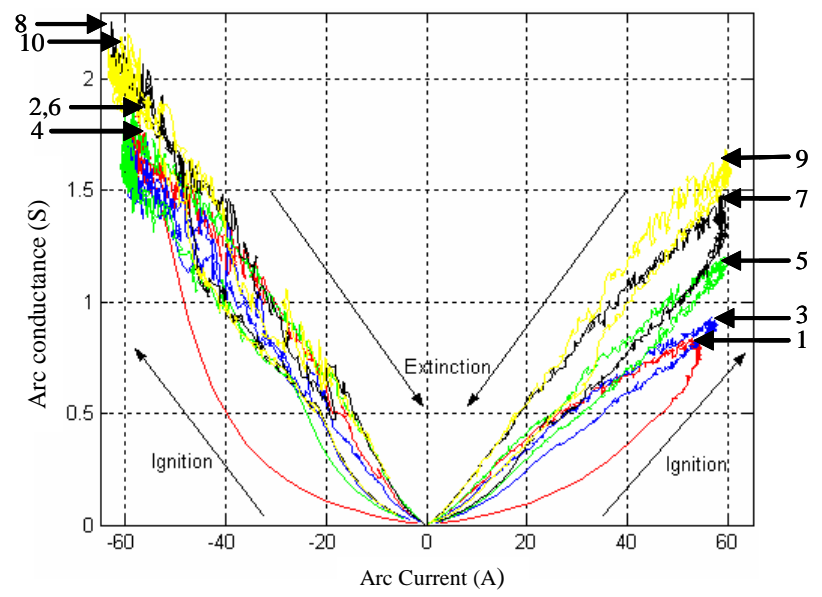

Figure 8. Arc conductance as a function of arc current for consecutive arcs. The arc starts at $104 \mathrm{~ms}$ in the positive half cycle of Figure 7c. The tip of each loop is assigned a number according to its sequential order.

\section{FULL CABLE ASSEMBLY FAILURE}

$\mathrm{LV}$ fault development was also investigated for a complete cable. In this case, three holes (10 mm diameter) were drilled into the sheath of the cable sample. The belt insulation of the cable was left intact. $20 \mathrm{~cm}$ of the cable was immersed in tap water. Temperature controlling probes were inserted into each of all four cores to heat the conductors at $75^{\circ} \mathrm{C}$ constantly. This cable sample was then inserted into the test circuit as described in Figure 2. Single-phase $240 \mathrm{~V}$ was applied continuously to the four conductors and the sheath was earthed, simulating a phase-to-earth fault development in an operational cable. Discharge signals were captured by the inductive PD sensor and Rocoil current transducer used previously. The sample preparation is shown in Figure 9.

A typical example of the current development between a core and earth is shown in Figure 10. In this case the current passes through the core insulation and the belt insulation which adds four layers of OIP. PD signals were observed intermittently on the oscilloscope after day 7. In general, the PD magnitude also shows a gradual increase. At day 28, an arc initiated immediately after a 15 minute period of intensive PD activity. In the following $24 \mathrm{~h}$, a series of arcs broke the insulation down leading to a final catastrophic failure.

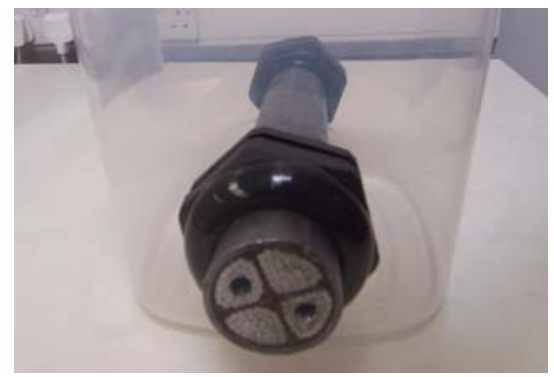

Figure 9. Full cable sample. Holes seen in two of the conductors are for heaters; there are also two at the other end of the other two conductors.

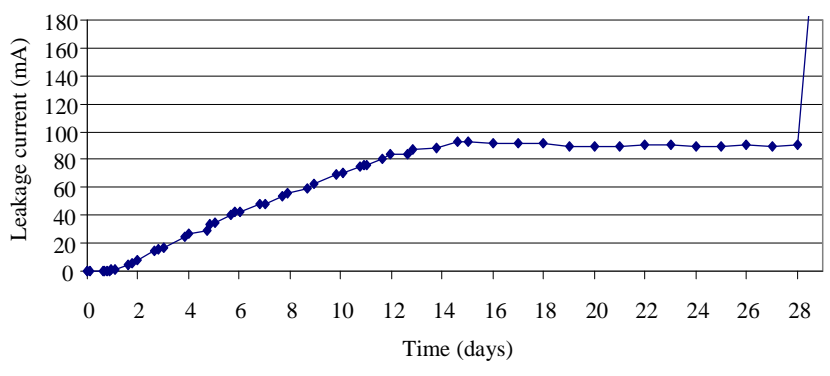

Figure 10. Current through full cable insulation with time, for penetrated sheath immersed in tap water, and cores heated to $75^{\circ} \mathrm{C}$.

Figure 11 shows the characteristics of consecutive arcing events in the full cable case. This is very similar to the behavior described for a single core immersed in water.

\section{PD AND ARC DATA ANALYSIS}

Based on the tests undertaken, a general trend can be found that increasing PD intensities would indicate an arc is going to initiate, but the PD intensity and/or its occurrence prior to or after an arc cannot at present, be used to predict precisely when and where an arc is going to strike. This work for LV equipment is at a much earlier stage than that reported for high voltage cables [13] and other equipment insulation [14]. Table 1 captures knowledge generated concerning the development of arcs in the work reported here.

a)

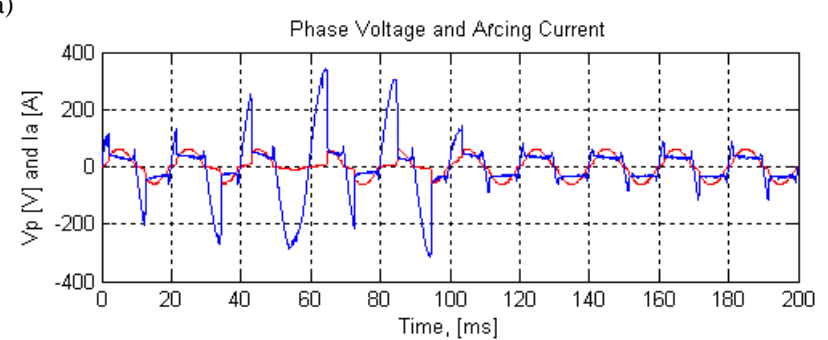

b)

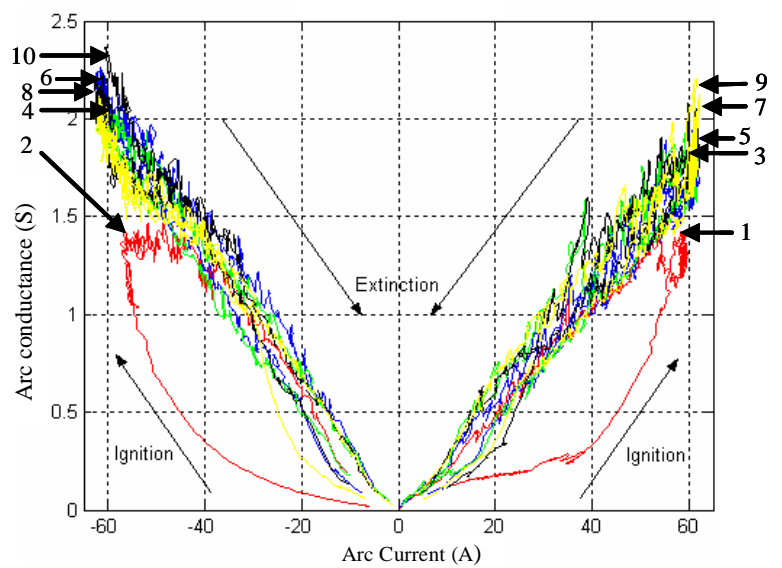

Figure 11. Characteristics of continuous arcs in the full cable case. The trace starts from $94 \mathrm{~ms}$ in the negative half cycle. The tip of each loop is assigned a number according to its sequential order. 
Table 1. Arc data analysis from all tests.

\begin{tabular}{|c|c|c|c|c|c|}
\hline Arc stage & Frequency of arc & $\begin{array}{l}\text { Arc conductance/ } \\
\text { current }\end{array}$ & $\begin{array}{c}\text { Maximum arc } \\
\text { conductance (S) }\end{array}$ & $\begin{array}{c}\text { Arc ignition } \\
\text { voltage (V) }\end{array}$ & $\begin{array}{l}\text { Arc duration } \\
\text { (ms) }\end{array}$ \\
\hline Initial & Single events & Large hysteresis & 0.3 & 50 & 3 \\
\hline Sporadic & A few per hour & & & & \\
\hline Intermittent & $\begin{array}{c}\text { Clusters of many } \\
\text { every few } \\
\text { minutes }\end{array}$ & & & & \\
\hline Continuous & 2 per cycle & No hysteresis & 2.8 & 10 & 8 \\
\hline
\end{tabular}

\section{TEMPERATURE CYCLING}

Figure 12 shows the results of heat cycling on wet core conductance. In this case the core conductors were heated and cooled for periods of $24 \mathrm{~h}$ under constant exposure to tap water for 12 cycles (576 h).

The graph shows that a rapid rise in core temperature results in a high increase in insulation conductance, which is reduced again during the following elevated temperature period. It can also be noted that the shape of the conductance curve is regular in the heating and cooling phases. This suggests that rapid temperature change has a significant effect on the insulation properties, leading to a sharp rise or fall of leakage current.

In the 48-h cycles, the insulation never recovers its original conductance values, and the overall effect is to continually 'ratchet' up the current. In the case shown here an equilibrium appears to have been reached after 9 cycles (450 h) so that cycles 10 to 12 are similar to each other. Heating and cooling cycles of $8 \mathrm{~h}$ and $16 \mathrm{~h}$ showed similar properties, reaching an equilibrium after 12 cycles $(300 \mathrm{~h})$. In both cases, after many cycles the minimum conductance was about $80 \mu \mathrm{S}$, whereas the maximum was $110 \mu \mathrm{S}$ for the rapid cycling and $160 \mu \mathrm{S}$ for the 48 -h cycle.

It is clear that a rapid increase in temperature of a wet cable leads to a transient increase in conductance. An investigation was therefore made to verify that reducing the heating rate reduces the peak rms current. Figure 13 shows the change of insulation conductance with three rates of cable temperature change. The change of temperature for the samples giving the triangle-marked curves is from $15{ }^{\circ} \mathrm{C}$ to $75{ }^{\circ} \mathrm{C}$ or from $15{ }^{\circ} \mathrm{C}$ to $105{ }^{\circ} \mathrm{C}$ in less than one hour, while the samples giving the circle-marked curves were heated up to $75{ }^{\circ} \mathrm{C}$ or $105{ }^{\circ} \mathrm{C}$ in steps of $30{ }^{\circ} \mathrm{C}$ every hour.

The transient change of current is reduced significantly for the $105{ }^{\circ} \mathrm{C}$ case by reducing the rate of temperature change. The faster rise in temperatures led to a higher conductance in the insulation for the duration of the tests. Repeated tests confirm this outcome. This indicates a potential threat of thermal runaway when rapidly increasing the load on a damaged cable especially in an overloading situation. Further tests are required to confirm and clarify whether slow loading of a defective cold cable can avoid increasing insulation damage and extend the cable's operational life.

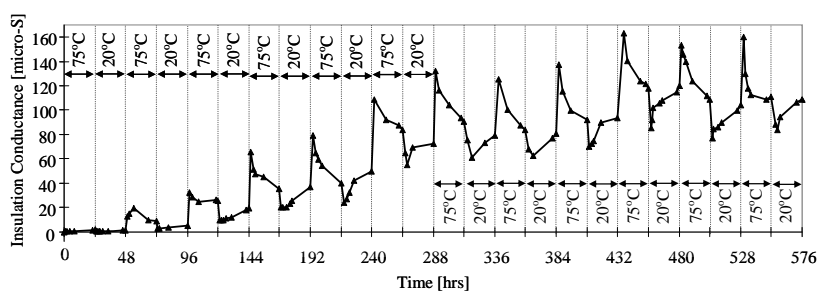

Figure 12. Change of insulation conductance during 48-hour heat cycling with the core exposed to tap water.

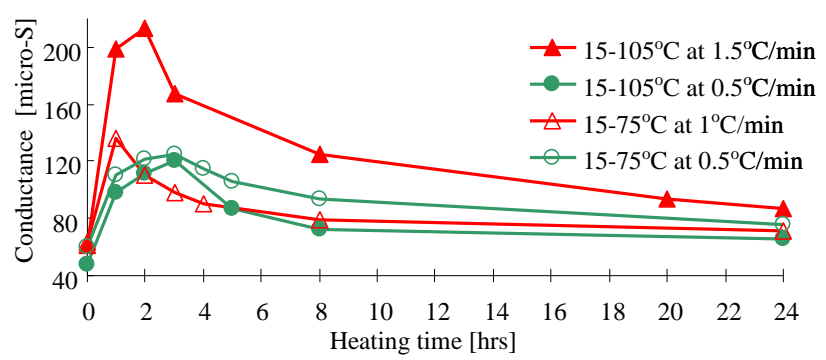

Figure 13. Impact of rate of change of temperature on a wet core.

\section{DISCUSSION}

Figure 4 reveals that for the case of a cable core at $75^{\circ} \mathrm{C}$, moisture has penetrated the innermost OIP layer to reach $3 \%$ when the current is $1 \mathrm{~mA}$ and over $5 \%$ at $100 \mathrm{~mA}$. It is reasonable to suppose that the moisture levels at the core, are controlling the conductance hence the current through the insulation. At $20^{\circ} \mathrm{C}$, a much higher moisture level of $13 \%$ was seen than at the elevated temperature when the current reached $100 \mathrm{~mA}$. The implication is that less moisture is required for high currents at elevated temperatures. The development of the current with time shown in Figure 3 reveals a number of different behaviours. 
Most notably, the more conductive water led to a much quicker increase in current as seen in Figure 3b. With tap water, a gradual increase was seen over days. One unexplained feature for the tap water case at $20^{\circ} \mathrm{C}$ is the step in the curves; a period when the current stops increasing for tens of hours at about $30 \mathrm{~mA}$ before increasing gradually prior to failure. A similar feature is seen in the whole cable assembly test at $75^{\circ} \mathrm{C}$ in Figure 10.

Figure 4 indicates that the build up of a highly conductive path requires a certain level of moisture as the preliminary condition for development of failure. After the moisture content has reached a certain threshold, a fault can continue to develop without further moisture increase. It has previously been shown that the inner layer saturates at a lower level and quicker at $75{ }^{\circ} \mathrm{C}(\sim 8 \%$ after $76 \mathrm{~h})$ than at $20^{\circ} \mathrm{C}(\sim 15 \%$ after $200 \mathrm{~h}$ ) [3]. The higher current reached faster in the elevated temperature case shown in Figure 3 may therefore be due to a more rapid rise of moisture levels and in particular achieving saturation faster. Based on the empirical data however, it might be considered that moisture content higher than 3\% should be considered a dangerous situation facilitating the build up of a conductivity path within the OIP insulation.

Figure 10 shows that the complete cable sample tested with a damaged sheath suffers from a similar increase in conductivity but over a longer period of time. A step is seen in this figure, representing a period where current remains steady for 13 days, before a rapid increase in current and final failure. It is unsurprising that the failure takes a longer time than for the cores directly soaked in moisture since in this case water has to penetrate an extra four layers of insulation. Also since the entry point for moisture to the insulation is limited, the water may not readily find the most porous part of the cable. As a result of this localized wetting, such an experiment is subject to considerable sample-to-sample variation. Thus care should be taken not to generalize too much on this one result.

The flow chart in Figure 14 identifies the development of electrical activity witnessed in these experiments and suggests a model of cable failure development. At present there is no qualitative description of the transitions between states. However, if an individual arc within a half cycle is identified, it appears its intensity is dependent upon the immediate history of the site.

The 'butterfly-wing' curves of Figures 8 and 11 and the summary in Table 1 may in future provide a fingerprint of a sporadic arc event. The shape and area of the loops shown in Figures 8 and 11 are dependent upon the arc current, arc ignition voltage and arc sustained voltage. These are dependent on the supply impedance as well as local factors and arc sample history. Generally speaking, the lower the arc ignition voltage the closer the loop will be to the linear extinction line. Study of the slope angle of the arc as well as the arc conductance and area of the loop may distinguish the arcs developed at different stages.

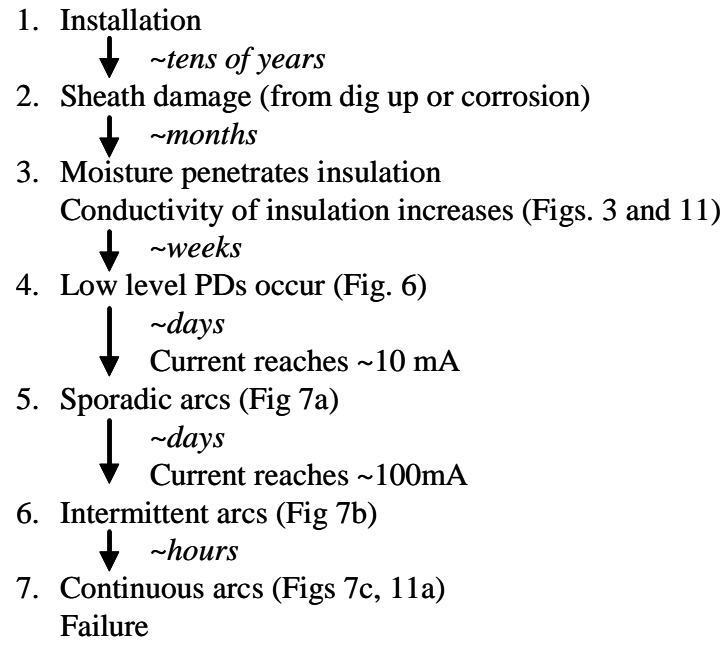

Figure 14. Model of failure stages.

In Figure 15 the maximum arc conductance is plotted against the maximum current during each successive half cycle for the sequence of arcs in Figure 8. These are labelled consecutively 1, 2, 3, etc. From this it can be seen that conductance is higher on the negative half cycle, and that the conductance increases in each alternate half cycle. This is particularly evident in the positive half cycles. It is conceivable that a tool might be developed which can judge the threat posed by an incipient fault based on analysis of this behaviour. However more work is required to understand the evident hysteresis effects.

It is clear that in the laboratory cases described here, a rapid increase in current occurs prior to failure. Figures 12 and 13 show that a rapid rise in core temperature can cause an associated transient, increase in current. These shortlived peaks in conductance of up to $200 \mu \mathrm{S}$ allow currents of $48 \mathrm{~mA}$ through a $20 \mathrm{~cm}$ length of cable insulation. It has not been shown that high currents are sufficient to cause ultimate failure but the numbers demonstrate that there is reason to expect problems if a cable temperature is increased rapidly when it contains moisture. Furthermore a slower ramping of temperature reduced the highest conductance seen, suggesting that this might be one way of protecting a cable at risk. Further work is required to confirm these suggestions.

Figure 12 also shows that when the temperature is reduced to $20{ }^{0} \mathrm{C}$ there is an immediate drop in conductance, followed by a slow rise. The rapid drop is likely to be due to the reduced mobility of ions with temperature and the slow rise is associated with continued diffusion of moisture into the cable as seen in Figure 10. This consideration shows that simple, steady-state models are unlikely to be sufficient to describe the behaviour of a working cable. 


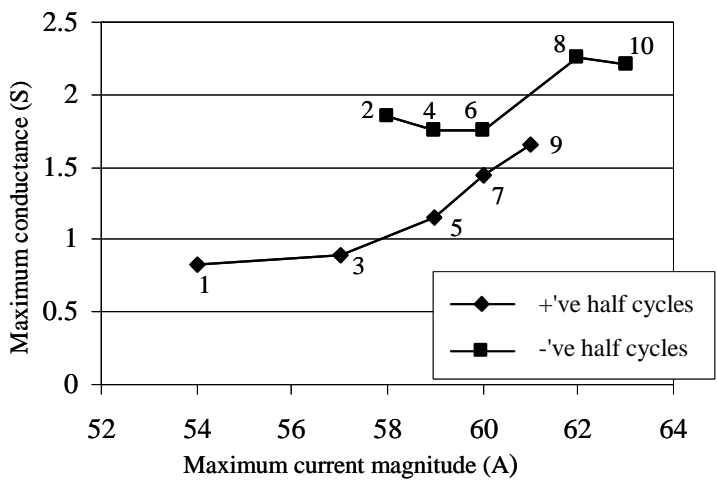

Figure 15. The maximum current and conductance seen on each half cycle for five cycles of arcing from the data shown in Figures 8, the sequence of half cycles is identified.

\section{CONCLUSIONS}

Measurements and observations of the failure process in low voltage $(240$ V) OIP insulated cables have been presented. It is suggested that moisture must penetrate the complete insulation for failures to occur. Once rms currents through the insulation of the cable lengths considered exceed $100 \mathrm{~mA}$, failure through discharges is swift. However the time taken to reach this state varied with cable temperature and moisture conductivity. High temperatures and moisture conductivity led to shorter times to cable failure.

The development of discharges has been associated with real cable damage. It has been shown that sporadic discharges can occur for many days before these develop into occasional arcs. These arcs can then develop into continuous discharges which destroy the cable insulation. The hysteresis of arc current/conductance curves can be used to identify the immediate history of an event. It is suggested that this might be used in future to characterize whether an event is likely to develop into a failure.

Rapid increased of wet insulation from room temperature to 75 or $105{ }^{\circ} \mathrm{C}$ has been shown to increase the leakage current through the insulation. This is the sort of temperature rise seen in service when ramping up a load. It is suggested that this presents an increased risk to the insulation. It has also been shown that a slower increase in core temperature leads to lower transient leakage currents.

\section{ACKNOWLEDGMENT}

The authors are grateful to EdF Energy for supporting this research, and for their permission to publish.

\section{REFERENCES}

[1] G. F. Moore, Ed., Electric Cables Handbook, Blackwell Science, 3rd edn, 1997.

[2] C.M. Walton, "Detecting and locating MV failure before it occurs", CIRED, paper 1.40, 2001.

[3] M. Wang, S. M. Rowland and P.E. Clements, "Moisture Ingress into Low Voltage Oil-Impregnated-Paper Insulated Distribution Cables", Accepted for publication: IET Proc. Sci, Tech and Meas.(UK).
[4] G.J. Bertini, "Molecular thermodynamics of water in direct buried power cables”, IEEE Electr. Insul. Mag., Vol. 22, No. 6, pp. 17-23, 2006

[5] S. Cherukupalli, V. Buchholz, M. Colwell, J.-P. Crine and R. J. Keefe, "Condition assessment of distribution PILC cables from electrical, chemical and dielectric measurements”, IEEE Electr. Insul. Mag., Vol. 20, No. 4, pp. 6-12, 2004.

[6] W.S. Zaengl, "Dielectric spectroscopy in time and frequency domain for HV power equipment, Part I: theoretical considerations”, IEEE Electr. Insul. Mag., 19, No. 5, pp. 5-19, 2003.

[7] S. M. Gubanski and P. Boss, "Dielectric response methods for diagnostics of power transformers”, IEEE Electr. Insul. Mag. Vol. 19, No.3, pp. 12-18, 2003.

[8] Y. Du, M. Zahn, B.C. Leseiutre, A.V. Mamishev and S.R.Lindgren, "Moisture equilibrium in transformer paper-oil systems", IEEE Electr. Insul. Mag., Vol. 15, No.1, pp. 11-20, 1999.

[9] R. Neimanis, T.K. Saha and R. Eriksson, "Determination of moisture content in mass impregnated cable insulation using low frequency dielectric spectroscopy”, IEEE Power Eng. Soc. Summer Meeting, Seattle, USA, pp. 463-468, 2000.

[10] R. Neimanis, R. Eriksson and R. Papazyan, "Diagnosis of moisture in oil/paper distribution cables-Part II: Water penetration in cable insulation - Experiment and modeling”, IEEE Trans. Power Del., Vol. 19, pp. 15-20, 2004.

[11] R. Neimanis and R. Eriksson, "Diagnosis of moisture in oil/paper distribution cables-Part I: Estimation of moisture content using frequency-domain spectroscopy”, IEEE Trans. Power Del., Vol. 19, pp. 9-14, 2004.

[12] J. Densley, "Ageing mechanisms and diagnostics for power cables an overview”, IEEE Electr. Insul. Mag., Vol. 17, Issue 1, pp. 14-22, 2001.

[13] G.C. Montinari, A. Cavallina, and F Puletti, "A new approach to partial discharge testing of HV cable systems”, IEEE Electr. Insul. Mag. Vol. 22, No. 1, pp. 14-23, 2006.

[14] G.C. Stone, "Partial discharge diagnostics and electrical equipment insulation condition assessment”, IEEE Trans. Dielectr. Electr. Insul., Vol. 12, pp. 891-903, 2005.

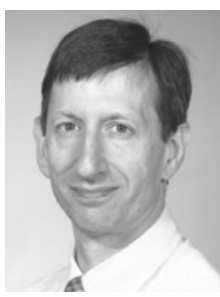

Simon M. Rowland (SM'07) was born in London, England. He completed his B.Sc. degree in physics at UEA and his Ph.D. at London University. He was awarded the IEE Duddell Premium in 1994 and became a FIET in 2000. He has worked for many years on dielectrics and their applications. He has also been Operations and Technical Director in a multinational manufacturing company. He joined The School of Electrical and Electronic Engineering in The University of Manchester as a Senior Lecturer in 2003.

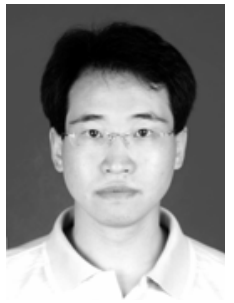

Miao Wang was born in Shen Yang, Liao Ning, China. He completed his B.Sc. in electrical power engineering at The Northeast Electric Power Institute in China in 2000 and his M.Sc. at UMIST in the UK in 2003. He recently completed his Ph.D. through research on condition assessment voltage cable failure and associated discharge characteristics in the School of Electrical and Electronic Engineering in The University of Manchester in the UK. 